\title{
Microdissection and molecular analysis of single cells or small cell clusters in pathology and diagnosis - Significance and challenges
}

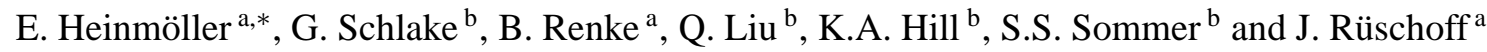 \\ a Institute of Pathology, Klinikum Kassel, Mönchebergstrasse 41-42, 34125 Kassel, Germany \\ ${ }^{\mathrm{b}}$ Department of Molecular Genetics, City of Hope National Medical Center/Beckman Research Center, \\ Duarte, CA 91010, USA
}

Received 13 August 2001

Accepted 24 July 2002

Abstract. Colour figures can be viewed on http://www.esacp.org/acp/2002/24-4_5/heinmoeller.htm.

\section{Introduction}

The pathologist of the future will not be content to identify morphologically altered cells within the context of the defined morphological compartment. He or she will want to genotype that cell to determine if genetic damage has occurred that may be relevant to the medical management of the patient. Hence, one of the most rapidly growing fields in modern pathology and diagnosis is the molecular analysis of single cells and small cell clusters microdissected from tissue sections mounted on glass slides and from cell smears or cytospins harvested for cytological diagnosis. In recent years, technical refinements have enabled PCRbased genetic analysis of minute amounts of genomic DNA or RNA obtained from as little as a single cell (Fig. 1) $[4,5,8,13,24,27,31,37,53]$. Based on the growing knowledge of the genetic defects underlying malignant and non-malignant pathological conditions, molecular data are increasingly used as valuable support for routinely performed histopathological diagnosis. Tissue or cell samples processed in routine pathology usually consist of heterogeneous cell populations which can frequently complicate precise molecular genetic

\footnotetext{
*Corresponding author: Klinikum Kassel, Institute of Pathology, Dr. Ernst Heinmöller, Mönchebergstrasse 41-42, 34125 Kassel, Germany. Tel: +49 561980 3228; Fax: +49 561980 6983; E-mail: eheinmoeller@klinikum-kassel.de.
}

analysis of the cell population in question. An important challenge in molecular pathology is the sampling error associated with microdissection that often leads to false negative or false positive results $[9,26]$. As a rule of thumb, the more homogeneous the cell population analysed, the more precise and reliable the molecular information obtained on the cell population under study. Current technologies permit molecular analyses of single cells.

\section{Microdissection techniques}

Microdissection of tissue samples facilitates the precise molecular analysis of the different steps during carcinogenesis based on morphological changes in preneoplastic lesions (Fig. 2). Tumours are heterogeneous due to infiltrating normal stromal or inflammatory cells and they contain genetically heterogeneous subpopulations that differ from normal cells by point mutations, loss of heterozygosity, and chromosomal abnormalities. Tumour cells forming the invasive part of the tumour may have genetic defects different from tumour cells at the centre of the lesion. Besides microdissection, in situ techniques like immunohistochemical staining of cells provide a valuable method to discriminate cell populations according to their phenotypic and functional characteristics in normal and diseased tissues. Combined with morphological features 


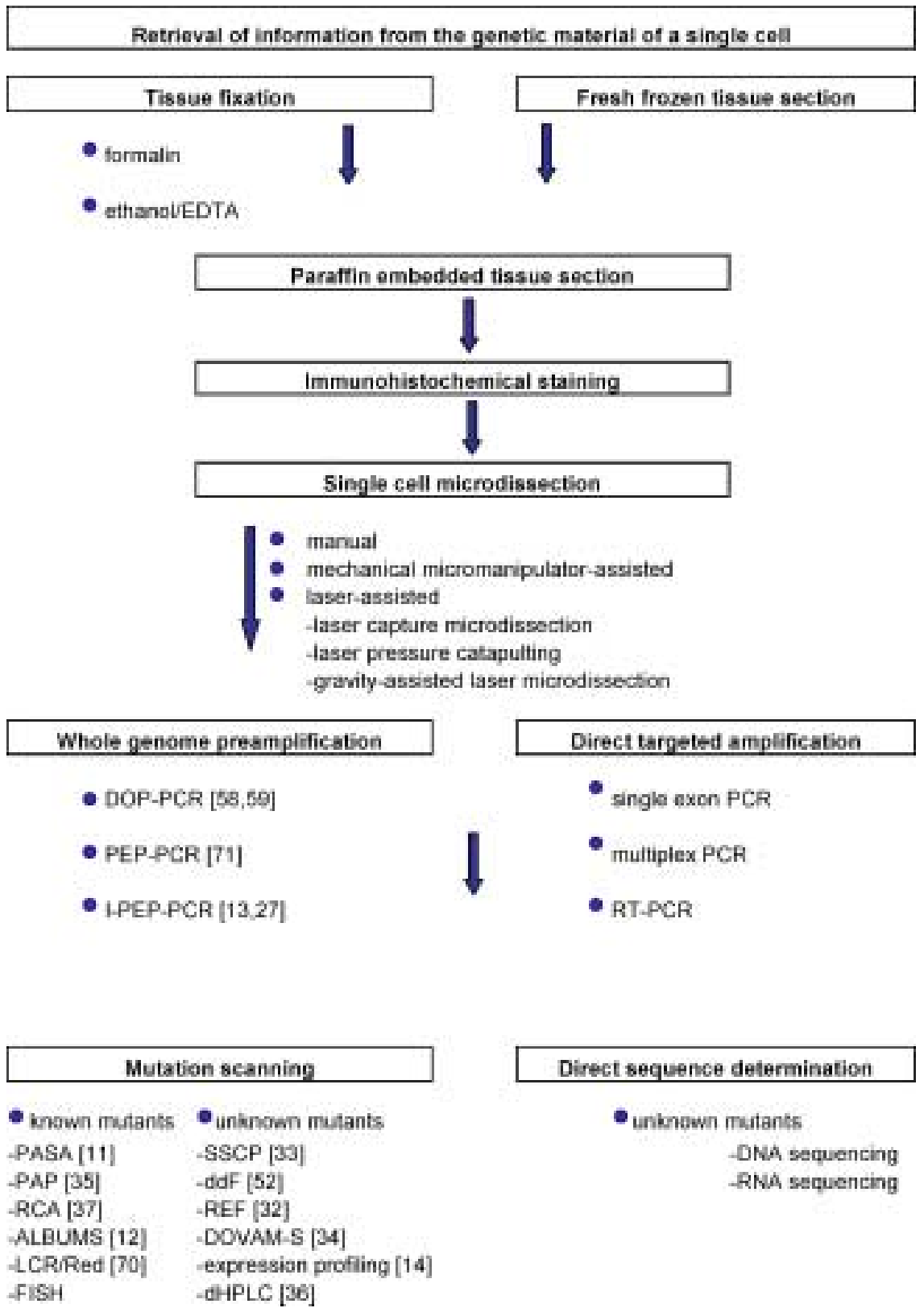

Fig. 1. Schematic demonstration of different possibilities to acquire genetic information using tissue microdissection. Nowadays, researchers can chose from a variety of methods depending on the desired information. This figure can be viewed on http://www.esacp.org/acp/2002/24-4_5/ heinmoeller.htm.

and immunohistochemistry, microdissection of defined cells or cell populations followed by molecular genetic analysis is a powerful approach to aid in better understanding the pathogenesis and progression of cancerous and non-cancerous diseases.

Two simple microdissection techniques are commonly employed. Manual microdissection of stained tissue sections mounted on glass slides can be per- formed using an inverted microscope and a sterile needle. This technique is simple and inexpensive. Precision of manual microdissection is limited, especially when tissue areas consisting of less than 50 cells are of diagnostic interest. The risk of contamination is also substantial. Another technique is microdissection aided by a mechanical micromanipulator, which is equipped, for example, with a glass or 


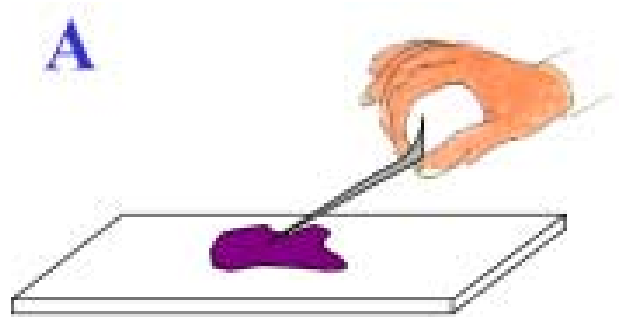

Manual microdissection

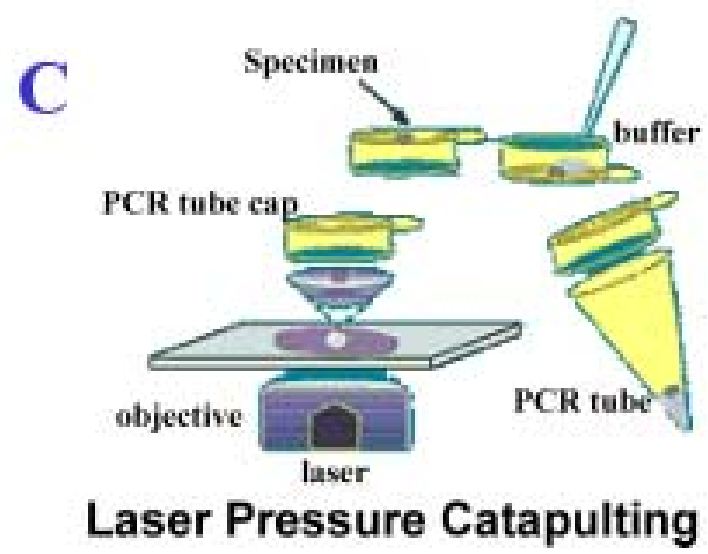

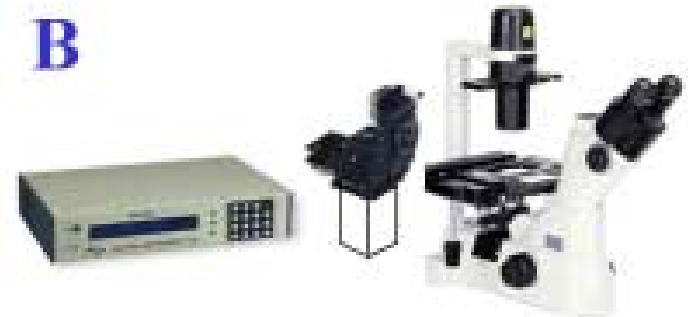

\section{Micromanipulator assisted microdissection}

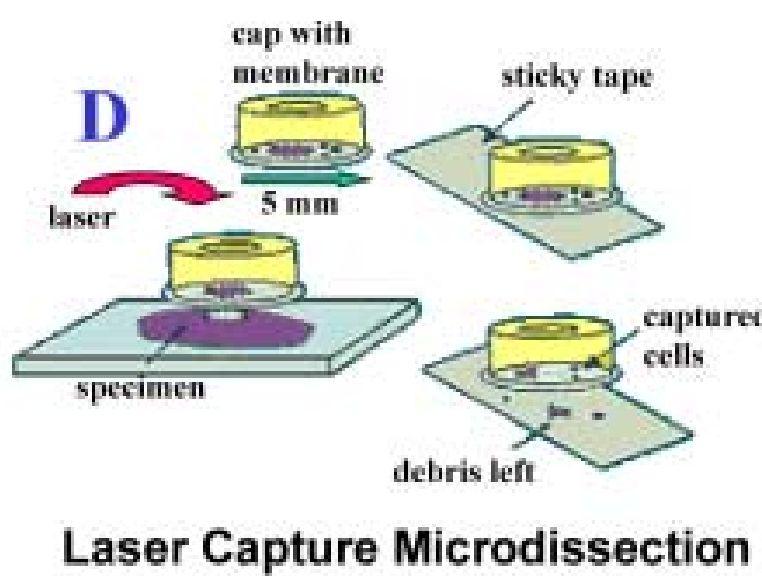

Fig. 2. A: Manual microdissection with surgical needle, w. or w/o optical magnification; B: Mechanical microdissection with joystick-operated robotic micromanipulator and inverted microscope; $\mathrm{C}$ : Laser-assisted microdissection using the laser to cut the sample and to transfer desired parts into tube mounted above the slide; D: Laser-assisted microdissection using foil-mounted tissue sections. This figure can be viewed on http://www.esacp.org/acp/2002/24-4_5/heinmoeller.htm

tungsten needle (Sutter Instruments, Novato, California, USA; http://www.sutter.com/) [21]. This relatively inexpensive technique enables precise microdissection down to the level of a single cell with only negligible risk of contamination [5,27]. Drawbacks of mechanical micromanipulator-guided microdissection are (i) time required for microdissection when many cells are processed, (ii) technical skill on the part of the operator, and (iii) lack of automation for cell collection.

An important advance was the development of laser microdissection technology (Fig. 2) [17]. This expensive technique uses focused pulsed ultraviolet light to cut tissue areas or single cells out of tissue sections with high precision and speed. At least four principles of laser-assisted tissue microdissection are used: (i) ablation of unwanted tissue by laser beam followed by mechanical picking of the lesion in question with a micromanipulator or a sterile needle [4], (ii) laser capture microdissection (LCM, Arcturus Engineering, Mountain View, California, USA; http://www.arctur.com) in which a focused laser beam melts a polymer membrane with the cells in question and lifting of the membrane transfers the bound tissue to a microcentrifuge tube containing cell lysis buffer [16], (iii) laser pressure catapulting microdissection (LPC, P.A.L.M., Microlaser Technologie, Bernried, Germany; http://www. palm-microlaser.com/) in which microdissected cells on a polymer membrane are catapulted by laser beam pressure into the lid of a microcentrifuge tube containing cell lysis buffer [53], (iv) gravity-assisted laser microdissection (Leica LMD; http://www.leicamicrosystems.com/) in which tissues that are mounted on a polymer membrane are inverted on the microscope stage and cells microdissected by a pulsed UVlaser fall into the microcentrifuge tube. Major advantages of the last three variants of laser-assisted microdissection are contamination-free collection of cells or tissues, speed of handling and the potential of computer-assisted automation of sample collection. These features are especially important considering the 
growing need for high throughput analysis of complex tissue areas, e.g., in the diagnosis of microsatellite instability in preneoplastic lesions of patients susceptible to HNPCC-syndrome [26] or in proteomics, where large amounts of proteins are needed for analysis (for review, see $[40,56])$.

\section{Molecular analysis of single cells or small cell numbers}

Micromanipulator-guided collection of single cells or small tissue areas and laser microdissection technologies meet the requirements of contamination free and precise, small sample collection. However, molecular analysis of minute amounts of DNA or RNA has several challenges. Tissue fixation is critical if molecular data obtained from small tissue samples are analysed. While tissue morphology is usually not altered significantly by various tissue fixation techniques, the quality of the DNA extracted from fixed tissues is affected if formalin, which is the most widely used fixative, is employed. Formalin causes DNA-degradation by cross-linking of DNA-molecules thereby limiting the efficiency of PCR amplification and the maximum achievable length of the PCR amplicon [29].

The detection of microsatellite instability (MSI) and loss of heterozygosity ( $\mathrm{LOH})$ are the most commonly used tests in diagnostic molecular pathology and basic research. For both tests to reach maximum reliability, the cell populations tested are required to be as homogeneous as possible. For example, microdissected tumour tissue should contain at least $70 \%$ neoplastic cells to enable detection of LOH [10]. The dissection of small tissue areas has been shown to be important to avoid false negative results, e.g., in the diagnosis of MSI [26] or LOH [9]. Precise laser-assisted microdissection of various areas of a flat villous adenoma with a small focus of colonic adenocarcinoma from a patient susceptible to HNPCC-syndrome revealed high grade MSI in the adenoma as well as in the carcinoma. No high grade MSI could be detected when the entire tissue section containing both lesions was collected. The study of Bertheau et al. [9] demonstrated that stromal cells may obscure detection of $\mathrm{LOH}$ in breast cancer samples. $\mathrm{LOH}$ analysis from whole tissue samples versus laser-assisted microdissection showed that $39 \mathrm{LOHs}$ of $55 \mathrm{LOHs}$ were not diagnosed when whole tumor samples were analyzed, which is a decrease of sensitivity of $71 \%$. The signifi- cance of sampling error in procurement of small tissue sample sizes lower than 30 cells has been demonstrated recently by Dietmaier et al. [13]. In this study, improved primer extension and preamplification PCR (IPEP-PCR), which is an improved technique of whole genome amplification originally described by Zhang et al. [71] was used. Limitations in the interpretation of PCR results from laser microdissection of small tissue samples or single cells from formalin-fixed tissues were clearly demonstrated. For reliable and reproducible diagnosis of $\mathrm{LOH}$ at least 10 unfixed cells from fluorescence-activated cell sorting, 10 cells from frozen tissue or at least 30 cells from formalin-fixed and paraffin-embedded tissue sections were required. When less than 10 or 30 cells, respectively, were amplified, false positive results were obtained in the diagnosis of $\mathrm{LOH}$. The results showed loss of one of the two alleles in LOH analysis of samples exhibiting no allelic loss when more than 30 cells were analysed.

In tissue sections, besides cross-linking of DNA molecules, loss of genetic material occurs with sectioning simply because of the three dimensional tissue structure. Loss of chromosomes or parts of chromosomes can lead to pseudo-LOH, dependent on section thickness. It is estimated that loss of chromosomal material occurs in 15 to $20 \%$ of nuclei in tissues sectioned routinely with $5 \mu \mathrm{m}$ thickness [13]. For this reason, microsatellite allele typing is not possible with single cells from sectioned tissues.

In a recent study, a correlation between the amount of DNA from formalin-fixed, paraffin-embedded tissues used for PCR amplification and the number of false positive sequence changes detected by sequence analysis was found. Williams et al. [69] recorded up to one mutation artifact per 500 bases analysed when 10 and 20 cells/PCR-reaction were templates in a nested PCR-set-up. No sequence artifacts were detected when frozen tissues were analysed. These data are of fundamental importance as formalin-fixed tissues are used routinely in biomedical research, and mutation databases usually contain data obtained from formalin-fixed tissues (e.g., 38\% of somatic TP53 mutations recorded in the IARC database originate from formalin-fixed tissues [69]). Interestingly, false positive mutations were not detected after sequencing of more than 4000 bases when 30 cells from formalinfixed tissues were preamplified by I-PEP-PCR [13]. The I-PEP-PCR mix contained Taq polymerase added with a pwo proofreading enzyme, which may greatly reduce the amount of PCR amplification errors usually introduced by Taq DNA polymerase (one in $2 \times 10^{5}$ to 
$2 \times 10^{3}$ bases amplified, $\left.[39,62]\right)$. However, the reasons for the presence of artificial mutations after sequence analysis of minute amounts of DNA may be more complex. As described by Williams et al. [69], mutation artifacts could be the consequence of formalin damaging or cross-linking of cytosine nucleotides. The Taq DNA polymerase incorporates an adenosine instead of a guanosine (because of the so-called A-rule) thereby creating a $\mathrm{C}>\mathrm{T}$ or $\mathrm{G}>\mathrm{A}$ mutation. In addition, damaged DNA may promote jumping between templates during enzymatic amplification. As a result, Taq DNA polymerase may then insert an adenosine residue when it reaches the end of a template molecule, then jump to another template and continue the extension thereby creating an artificial mutation. Consequently, the lower the amount of DNA used as starting material, the higher the chance that a damaged DNA molecule will lead to the creation of an artificial mutation during the first rounds of amplification. Higher amounts of DNA templates (30 cells in the study of Dietmaier et al. [13] and $>300$ cells in the study of Williams et al. [69]) were found sufficient to let intact templates dominate the amplification process thereby suppressing the amplification of damaged templates.

Critical factors influencing the outcome of PCR amplification of DNA or RNA with subsequent sequence analysis are the concentration of formalin used for fixation, the use of neutral buffered formalin versus nonbuffered formalin and the duration of fixation. The use of neutral buffered formalin and formalin concentrations in a range of 2 to $4 \%$ minimizes DNA or RNA cross-linking, and the prolonged formalinfixation of tissues (more than 24 hours) increases DNA cross-linking [7,68]. The impact of formalin-fixation on RNA extraction out of paraffin embedded tissues was less strong, most probably due to the presence of higher copy numbers of RNA-molecules in microdissected cells $[22,28]$. It is important to note that all studies cited above found the use of fresh frozen tissues or ethanol-fixed tissues superior to formalin-fixed tissues with regard to DNA recovery, amplification efficiency, length of amplified segments and the precise error-free sequence analysis after specific amplification. In addition, for clear and crisp immunohistochemical staining (e.g., for the presence of mutated TP53 and thereby stabilized p53 protein), ethanol-fixation is the method of choice compared to formalin-fixation or the less commonly used fixatives like Bouin's solution [1,2,27].

\section{Molecular analyses from single cells facilitated by whole genome amplification}

In general, PCR-technology is powerful enough to amplify segments of various lengths from diploid single cell genomes and even from haploid genomes recovered from sperm cells for subsequent molecular analysis. The most widespread strategy employed is a nested PCR-set-up which, when performed as a multiplex PCR can amplify more than 20 segments simultaneously in one reaction tube [55]. However, no subsequent PCR (e.g., PCR to confirm an identified mutation), can be performed after a nested PCR from a single cell. To overcome these limitations, whole genome amplification (WGA) PCR-techniques have been developed in which genomes from single or few cells are pre-amplified in a nonspecific, random manner thereby creating multiple copies (30 to several hundreds) [60] of the single cell genome. This enables multiple subsequent specific PCRs of any region of the genome of interest. Most commonly used WGA-techniques are degenerate oligonucleotide primer-PCR (DOP-PCR) [58, 59] and primer extension and preamplification PCR (PEP-PCR) [71]. DOP-PCR uses primers which have defined sequences at the $5^{\prime}$ and $3^{\prime}$ termini. Between these regions is a random hexamer sequence. PCR is performed under low stringency conditions during the first five cycles followed by 35 cycles with a more stringent annealing temperature. PEP-PCR uses totally degenerate primers which are 15 nucleotides long. Primers are allowed to anneal at a low temperature $\left(37^{\circ} \mathrm{C}\right)$ which is then continuously increased up to $55^{\circ} \mathrm{C}$. It has been reported that PEP-PCR and DOPPCR amplify more than $95 \%$ of the genome $[3,6]$ with PEP-PCR amplification covering slightly more of the genome than DOP-PCR [67]. The feasibility of WGA techniques has been demonstrated in up to 90 specific molecular analyses even for comparative genomic hybridization from single cells [67]. PEP-PCR protocols have been improved recently to enable multiple mutation analyses from paraffin-embedded tissues from as little as a single cell [13,27].

Molecular analysis of single cells has been performed routinely in fields like reproductive medicine for more than a decade [24]. Other fields of interest for molecular genetic single cell analysis are the clonal analysis of T-cell receptor repertoire of CD8+ T-cells after antigenic stimulation [41], clonal analysis of immunoglobulin rearrangements in Reed-Sternberg cells in Hodgkin's disease [64] and the detection of micrometastatic tumour cells in blood, lymph nodes or bone marrow to identify patients who may (or may not) benefit from adjuvant therapy [44]. 


\section{Identification of rare alleles}

Microdissection of single cells from histological sections from normal and tumour tissues permits precise analysis of rare heterozygous mutations. Cancer arises in multiple steps due to generation and accumulation of mutations $[38,63,65]$. For example, in some tissues like the pancreas, mutations in the TP53 gene or the $p 16^{I N K 4 A}$ gene may be among the first genetic alterations occurring in morphologically normal appearing tissues or preneoplastic lesions representing the very first steps in molecular carcinogenesis [25]. It is of great interest to develop a mutation detection technique, which detects rare heterozygous mutations in small tissue samples at the level of a single cell. This would enable the determination of an individual mutation load and could be the basis for an individual cancer risk assessment for persons being exposed to various exogenous hazards or at risk for cancer due to an endogenous predisposition (e.g., the $\mathrm{Li}$ Fraumeni syndrome). The first steps have been performed toward the development of such an assay that measures this mutation load. For example, Wilson et al. [70] have described a technique where PCR and ligase chain reaction in combination with restriction endonuclease digestion has been adapted for the detection and identification of mutations in oncogenic loci which do or do not contain a natural restriction endonuclease recognition sequence. The sensitivity reported in this study was the detection of one mutant allele in DNA equivalent to $10^{6}$ cells. In the protocol described by Chakrabarti et al. [12] for detection of unknown mutations, formation of heteroduplexes occurs in wild type DNA sample mixed with a DNA sample of question containing putative mutations. By a technique called Aldehyde-Linker-Based Ultrasensitive Mismatch Scanning (ALBUMS) with subsequent PCR-amplification of mutated DNA fragments, base substitution mutations can be detected with a detection limit of 1 base in $7 \mathrm{Mb}$ of DNA. However, both techniques suffer from a major drawback, i.e., a detected mutation cannot be directly associated with a particular tissue compartment or cell of the tissue specimen in question.

A PCR-technique which allows the detection of rare alleles of a known mutation (e.g., a mutation in the TP53 gene or other tumour suppressor genes previously identified within a tumour) is PCR-amplification of specific alleles (PASA) [11]. For PASA, an oligonucleotide primer is designed to amplify preferentially one allele (the mutant allele) over another (the wild type allele). Specificity is obtained if the oligonucleotide matches the desired allele, but mismatches the other allele(s) at or near the $3^{\prime}$ end of the allele specific primer. Single base changes, deletions, and insertions in DNA can be detected rapidly. This technique has a specificity of less than or equal to 1 part in 40 . Detection of minimal residual disease (rare remaining cancer cells during remission) is one of many applications of this mutation screening technique, and technical improvements which have the potential to enhance dramatically the specificity of PASA have been published recently [35].

Another highly sophisticated PCR-technique for detection of known mutations or analysis of small target DNA sequences as small as 50 nucleotides is rolling circle DNA amplification (RCA, for excellent detailed technical description, see [72]). This method uses circularised oligonucleotide probes for replication of small target sequences with either linear or geometric kinetics under isothermal conditions [37,43,72]. Replication products are visualized by coupling nucleic acid hybridisation and multicolour fluorescence imaging. The sensitivity of RCA is sufficient to detect individual oligonucleotide hybridisation events, e.g., in single cells or in stretched DNA fibers [72], and single antigen-antibody complexes on glass surfaces [54]. The feasibility of this technique has been demonstrated recently by visualization of point mutations in commonly analysed genes like the cystic fibrosis transmembrane conductance regulator, TP53, BRCA-1 and Patched. In addition, haplotyping of single human cells by in situ hybridisation of allele discriminating oligonucleotides to genomic DNA could be demonstrated in this study [72]. Ladner et al. [30] combined ligase detection reaction with RCA on a generic microarray which enabled the simultaneous detection of 17 mutational hotspots from multiplex ligation reactions, providing the basis for microarray based highthroughput automation. However, RCA-technique still needs major improvements as, e.g., the signals in interphase nuclei fluctuates between 20 and $55 \%$ of potentially accessible DNA target sequences. In reproductive medicine, genotyping of single cells from blastomeres would require an efficiency of $100 \%$, the detection of somatic mutations would require an efficiency of $>80 \%$. In addition, the signal intensity derived from in situ RCA from formalin-fixed histological sections is still low [72].

Few studies have analysed rare heterozygous mutations in single cells microdissected from fixed, paraffinembedded and immunohistochemically-stained tissue 
sections $[4,49,53,59]$. Overall, these studies were hampered by low amplification efficiency. A maximum of $30 \%$ of single cell genomes could be successfully amplified only when segments below $200 \mathrm{bp}$ in length were chosen [4]. Although some studies have analysed DNA from immunohistochemically-stained single cells from fresh frozen tissue samples [45, 46], only one study has conducted whole genome amplification prior to specific amplification of single cell genomes from fixed, paraffin-embedded and immunohistochemically-stained tissue sections [27]. In this study, rare, single and morphologically normalappearing cells overexpressing p53 protein were microdissected from ethanol-fixed, paraffin-embedded and immunohistochemically-stained sections of normal human tissue. Single cells were amplified by a modified PEP-PCR protocol that enabled sequence analysis of exons 5 to 9 of the TP53 gene in $50 \%$ of microdissected single cells. In these cells sequence changes were found in 5 out of 25 cells analyzed.

\section{Allele drop out}

As described earlier, molecular analysis of small cell samples is prone to several challenges like false positive LOH- or MSI-analysis. This is even more significant when single cell genomes are analysed. Allele drop out (ADO) is a tissue preparation and PCR related phenomenon where one allele is preferentially amplified over the other allele or where one allele is absent after amplification. ADO occurs in particular when templates consisting of DNA from less than 10 cells are amplified and occurs at the same rate regardless of whether nested PCR or whole genome amplification is used for initial amplification [23]. In reproductive medicine ADO remains a serious problem in the diagnosis of heterozygous mutations in single cells harvested from embryos at the blastomere stage. For example, in the case where both partners carry the same genetic mutation, ADO may result in genotyping the fetus either as homozygous normal or homozygous affected. In the latter case, an otherwise non-affected child may be aborted. If both partners carry different mutations at a genetic locus, as frequently occurs in regions where hemoglobinopathies are endemic, ADO may lead to a misdiagnosis which will lead to birth, or death in utero, of an affected child [24]. Depending on the source and quality of DNA amplified, ADO rates between 0 and $83 \%$ have been reported [18-20,23,48, $57,67]$. The allele that drops out during PCR amplifica- tion occurs at random. The occurrence of ADO is influenced by multiple factors, e.g., tissue sectioning, cell lysis, ingredients of PCR mix, thermal cycling conditions, guanine/cytosine content of the DNA-segment amplified or DNA template degradation $[15,47,66]$. No method described to date has been able to solve ADO. Despite the high ADO rate found in studies in which single cells from (fixed) tissue samples were analyzed, mutation analysis may be feasible in single cells embedded in paraffin. Heterozygous mutations may not be as frequent and mutations of at least one allele will be detected in all cases in which amplification of the wild type allele is lost by $\mathrm{LOH}$ (e.g., the typical way of TP53-inactivation in the majority of cases).

In conclusion, a variety of well designed studies have explored the limits of PCR amplification and subsequent molecular analysis. This was done using single cells or small cell numbers dissected from formalinor ethanol-fixed tissues or from fresh frozen tissues, which are routinely collected and handled in pathology departments all over the world. It is expected that future technical developments will facilitate the speed and automation of the microdissection process. However, serious challenges in the analysis of molecular data obtained from amplification of single cell genomes will continue to require special attention. Optimized protocols for tissue processing and PCR amplification are needed to gain access to the very first molecular genetic changes responsible for initiation and promotion of carcinogenic processes in human tissues. Furthermore, the engineering of polymerases with higher processivity may even enable high throughput molecular genetic analyses from single cells perhaps using microchip technology, which is currently not possible due to the small amount of PCR product after WGA. In the future, this may deepen our biological understanding of pathologic processes in general as well as enable the development of assays in which an individual mutation load can be determined to assess individual cancer risk.

\section{References}

[1] M.M. Arnold, S. Srivastava, J. Fredenburgh, C.R. Stockard, R.B. Myers and W.E. Grizzle, Effects of fixation and tissue processing on immunohistochemical demonstration of specific antigens, Biotechnic \& Histochemistry 71 (1996), 224-230.

[2] A.V. Bassarova and A.A. Popov, Immunohistochemical detection of p53 - effect of fixation and methods of antigen retrieval, Folia Histochemica et Cytobiologica 26 (1998), 127-132. 
[3] J.C. Beck, C.H. Kim, M.L. Hoover and R.A. Mulivor, Whole genome amplification of genomic DNA: Implications for multiple analyses of tumour samples, Proc. Am. Assoc. Cancer Res. 37 (1996), 570.

[4] I. Becker, K.F. Becker, M.H. Röhrl, G. Minkus, K. Schütze and H. Höfler, Single-cell mutation analysis of tumors from stained histologic slides, Lab. Invest. 75 (1996), 801-807.

[5] C.P. Beltinger, F. Klimek and K.M. Debatin, Whole genome amplification of single cells from clinical peripheral blood smears, J. Clin. Pathol: Mol. Pathol. 50 (1997), 272-275.

[6] P. Bender, M. Hoover, J. Byar, J. Leonhard and J.C. Beck, Representative whole genome amplification, Am J. Hum. Genet. 60(Suppl.) (1997), A231.

[7] J. Ben-Ezra, D.A. Johnson, J. Rossi, N. Cook and A. Wu, Effect of fixation on the amplification of nucleic acids from paraffinembedded material by the polymerase chain reaction, J. Histochem. Cytochem. 39 (1991), 351-354.

[8] M.R. Bernsen, H.B. Dijkman, E. de Vries, C.G. Figdor, D.J. Ruiter, G.J. Adema and G.N. Muijen, Identification of mRNA and DNA sequences from small tissue samples isolated by laser-assisted microdissection, Lab. Invest. 78 (1998), 12671273.

[9] P. Bertheau, L.F. Plassa, F. Lerebours, A. de Roquancourt, E. Turpin, R. Lidereau, H. de The and A. Janin, Allelic loss detection in inflammatory breast cancer: improvement with laser microdissection, Lab. Invest. 81 (2001), 1397-1402.

[10] M. Boehm and I. Wieland, Analysis of tumour-specific alterations in native specimens by PCR: How to procure the tumour cells, Int. J. Oncol. 10 (1997), 131-139.

[11] C.D. Bottema and S.S. Sommer, PCR amplification of specific alleles: rapid detection of known mutations and polymorphisms, Mutat. Res. 288 (1993), 93-102.

[12] S. Chakrabarti, B.D. Price, S. Tetradis, E.A. Fox, Y. Zhang, G. Maulik and G.M. Makrigiorgos, Highly selective isolation of unknown mutations in diverse DNA fragments: Toward new multiplex screening in cancer, Cancer Res. 60 (2000), 37323737.

[13] W. Dietmaier, A. Hartmann, S. Wallinger, E. Heinmöller, T. Kerner, E. Endl, K.W. Jauch, F. Hofstädter and J. Rüschoff, Multiple mutation analyses in single tumour cells with improved whole genome amplification, Am. J. Pathol. 154 (1999), 83-95.

[14] J. Eberwine, J.E. Kacharmina, C. Andrews, K. Miyashiru, T. McIntosh, K. Becker, T. Barrett, D. Winkle, G. Dent and P. Marciano, MRNA expression analysis of tissue sections and single cells, J. Neurosci. 21 (2001), 8310-8314.

[15] N. El-Hashemite and J.D.A. Delhanty, A technique for eliminating allele specific amplification failure during DNA amplification of heterozygous cells for preimplantation diagnosis, Mol. Hum. Reprod. 3 (1997), 975-978.

[16] M.R. Emmert-Buck, R.f. Bonner, P.D. Smith, R.F. Chuaqui, Z. Zhuang, S.R. Goldstein, R.A. Weiss and L.A. Liotta, Laser capture microdissection, Science 274 (1996), 998-1001.

[17] F. Fend and M. Raffeld, Laser capture microdissection in pathology, J. Clin. Pathol. 53 (2000), 666-672.

[18] I. Findlay, P. Ray, P. Quirke, A. Rutherford and R. Lilford, Allelic drop-out and preferential amplification in single cells and human blastomeres: implications for preimplantation diagnosis of sex and cystic fibrosis, Mol. Hum. Reprod. 10 (1995), 1609-1618.
[19] I. Findlay, M. Matthews and P. Quirke, Multiple genetic diagnoses from single cells using multiplex PCR: Reliability and allele drop out, Prenat. Diagn. 18 (1998), 1413-1421.

[20] A.M. Garvin, W. Holzgreve and S. Hahn, Highly accurate analysis of heterozygous loci by single cell PCR, Nucleic Acids Res. 15 (1998), 3468-3472.

[21] J.J. Going and R.F. Lamb, Practical histological microdissection for PCR analysis, J. Pathol. 179 (1996), 121-124.

[22] S.M. Goldsworthy, P.S. Stockton, C.S. Trempus, J.F. Foley and R.R. Maronpot, Effects of fixation on RNA extraction and amplification from laser capture microdissected tissue, Mol. Carcinog. 25 (1999), 86-91.

[23] S. Hahn, A.M. Garvin, E. Di Naro and W. Holzgreve, Allele drop-out can occur in alleles differing by a single nucleotide and is not alleviated by preamplificaton or minor template increments, Genetic Testing 2 (1998), 351-355.

[24] S. Hahn, X.Y. Zhong, C. Troeger, R. Burgemeister, K. Gloning and W. Holzgreve, Current applications of single-cell PCR, Cell. Mol. Life Sci. 57 (2000), 96-105.

[25] E. Heinmöller, W. Dietmaier, H. Zirngibl, P. Heinmöller, W. Scaringe, K.W. Jauch, F. Hofstädter and J. Rüschoff, Molecular analysis of microdissected tumors and preneoplastic intraductal lesions in pancreatic carcinoma, Am. J. Pathol. 157 (2000), 8392.

[26] E. Heinmöller, B. Renke, K. Beyser, W. Dietmaier, C. Langner and J. Rüschoff, Pitfalls in diagnostic molecular pathology - significance of sampling error, Virchows Arch. 439 (2001), 504-511.

[27] E. Heinmöller, L. Qiang, Y. Sun, G. Schlake, K.A. Hill, L.M. Weiss and S.S. Sommer, Towards the efficient analysis of mutations in single cells from immunohistochemically-stained ethanol-fixed paraffin-embedded cells, Lab. Invest. 82 (2002), 443-453.

[28] T. Inoue, K. Nabeshima, H. Kataoka and M. Koono, Feasibility of archival non-buffered formalin-fixed and paraffin-embedded tissues for PCR amplification: An analysis of resected gastric carcinoma, Pathol. Int. 46 (1996), 997-1004.

[29] F. Karlsen, M. Kalantari, M. Chitemerere, B. Johansson and B. Hagmar, Modifications of human and viral deoxyribonucleic acid by formaldehyde fixation, Lab. Invest. 71 (1994), 604611.

[30] D.P. Ladner, J.H. Leamon, S. Hamann, G. Tarafa, T. Strugnell, D. Dillon, P. Lizardi and J. Costa, Multiplex detection of hotspot mutations by rolling circle-enabled universal microarrays, Lab. Invest. 81 (2001), 1079-1086.

[31] G. Ling, A. Persson, B. Berne, M. Uhlen, J. Lundeberg and F. Ponten, Persistent p53 mutations in single cells from normal human skin, Am. J. Pathol. 159 (2001), 1247-1253.

[32] Q. Liu and S.S. Sommer, Restriction endonuclease fingerprinting (REF): a sensitive method for screening mutations in long, contiguous segments of DNA, BioTechniques 18 (1995), 470477.

[33] Q. Liu and S.S. Sommer, The SSCP phenomenon: addition of HEPES buffer dramatically affects electrophoretic mobility, BioTechniques 25 (1998), 50-56.

[34] Q. Liu, J. Feng, C. Buzin, C. Wen, G. Nozari, A. Mengos, V. Nguyen, J. Liu, L. Crawford, F.K. Fujimura and S.S. Sommer, Detection of virtually all mutations-SSCP (DOVAM-S): a rapid method for mutation scanning with virtually $100 \%$ sensitivity, BioTechniques 26 (1999), 932-942. 
[35] Q. Liu and S.S. Sommer, Pyrophosphorolysis-activated polymerization (PAP): Application to allele-specific amplification, BioTechniques 29 (2000), 1072-1083.

[36] W. Liu, D.I. Smith, K.J. Rechtzigel, S.N. Thibodeau and C.D. James, Denaturating high performance liquid chromatography (DHPLC) used in the detection of germline and somatic mutations, Nucleic Acid Res. 26 (1998), 1396-1400.

[37] P.M. Lizardi, X. Huang, Z. Zhu, P. Bray-Ward, D.C. Thomas and D.C. Ward, Mutation detection and single-molecule counting using isothermal rolling-circle amplification, Nat. Genet. 19 (1998), 225-232.

[38] L.A. Loeb, A mutator phenotype in cancer, Cancer Res. 61 (2001), 3230-3239.

[39] K.S. Lundberg, D.D. Shoemaker, M.W. Adams, J.M. Short, J.A. Sorge and E.J. Mathur, High-fidelity amplification using a thermostable DNA polymerase isolated from Pyrococcus furiosus, Gene 108 (1991), 1-6.

[40] D.B. Martin and P.S. Nelson, From genomics to proteomics: techniques and applications in cancer research, Trends Cell. Biol. 11 (2001), 60-65.

[41] J.L. Maryanski, C.V. Jongeneel, P. Bucher, J.L. Casanova and P.R. Walker, Single-cell PCR analysis of TCR repertoires selected by antigen in vivo: A high magnitude of CD8 response is comprised of very few clones, Immunity 4 (1996), 47-55.

[42] K.B. Mullis and F.A. Faloona, Specific synthesis of DNA in vitro via a polymerase-catalyzed chain reaction, Methods Enzymol. 155 (1987), 335-350.

[43] M. Nilsson, H. Malmgren, M. Samiotaki, M. Kwiatkowski, B.P. Chowdhary and U. Landegren, Padlock probes: circularizing oligonucleotides for localized DNA detection, Science $\mathbf{2 6 5}$ (1994), 2085-2088.

[44] K. Pantel and M. Otte, Identification and characterisation of minimal residual disease in solid tumors, Acta Med. Austriaca 27 (2000), 8-12.

[45] A.E. Persson, G. Ling, C. Williams, H. Bäckvall, J. Ponten, F. Ponten and J. Lundeberg, Analysis of p53 mutations in single cells obtained from histological tissue sections, Anal. Biochem. 287 (2000), 25-31.

[46] F. Ponten, C. Williams, G. Ling, A. Ahmadian, M. Nister, J. Lundeberg, J. Ponten and M. Uhlen, Genomic analysis of single cells from human basal cell cancer using laser-assisted capture microscopy, Mutat. Res. Genomics 382 (1997), 45-55.

[47] P. Ray and A.H. Handyside, Increasing the denaturation temperature during the first cycles of amplification reduces allele dropout from single cells for preimplantation genetic diagnosis, Mol. Hum. Reprod. 2 (1996), 213-218.

[48] S. Rechitsky, M. Freidine, Y. Verlinsky and C.M. Strom, Allele drop out in sequential PCR and FISH analysis of single cells (cell recycling), J. Assist. Reprod. Genet. 13 (1996), 115-124.

[49] M.H. Roehrl, K.F. Becker, I. Becker and H. Höfler, Efficiency of single-cell polymerase chain reaction from stained histologic slides and integrity of DNA in archival tissues, Diagn. Mol. Pathol. 6 (1997), 292-297.

[50] R.K. Saiki, S. Scharf, F.A. Faloona, K.B. Mullis, G.T. Horn, H.A. Erlich and N. Arnheim, Enzymatic amplification of betaglobin genomic sequences and restriction site analysis for diagnosis of sickle cell anaemia, Science 230(4732) (1985), 13501354.
[51] R.K. Saiki, D.H. Gelfant, S. Stoffel, S.J. Scharf, R. Higuchi, G.T. Horn, K.B. Mullis and H.A. Erlich, Primer-directed enzymatic amplification of DNA with a thermostable DNA polymerase, Science 239 (1988), 487-491.

[52] G. Sarkar, H.S. Yoon and S.S. Sommer, Dideoxy fingerprinting (ddF): a rapid and efficient screen for the presence of mutations, Genomics 13 (1992), 441-443.

[53] K. Schütze and G. Lahr, Identification of expressed genes by laser-mediated manipulation of single cells, Nat. Biotechnol. 16 (1998), 737-742.

[54] B. Schweitzer, S. Wildshire, J. Lambert, S. O'Malley, K. Kukanskis, Z. Zhu, S.F. Kingsmore, P.M. Lizardi and D.C. Ward, Inaugural article: immunoassays with rolling circle DNA amplification: a versatile platform for ultrasensitive antigen detection, Proc. Natl. Acad. Sci. USA 97 (2000), 10 113-10 119.

[55] A.P. Shuber, V.J. Grondin and K.W. Klinger, A simplified procedure for developing multiplex PCRs, Genome Res. 5 (1995), 488-493.

[56] R.J. Simpson and D.S. Dorow, Cancer proteomics: from signaling networks to tumor markers, Trends Biotechnol. 19 (2001), $40-48$.

[57] M.C. Snabes, S.S. Chong, S.B. Subramanian, K. Kristjansson, D. DiSepio and M.R. Hughes, Preimplantation single-cell analysis of multiple genetic loci by whole-genome amplification, Proc. Natl. Acad. Sci. USA 91 (1994), 6181-6185.

[58] M.R. Speicher, S. du Manoir, E. Schrock, H. Holtgreve-Grez, B. Schoell, C. Lengauer, T. Cremer and T. Ried, Molecular cytogenetic analysis of formalin-fixed, paraffin-embedded solid tumors by comparative genomic hybridization after universal DNA-amplification, Hum. Mol. Genet. 2 (1993), 1907-1914.

[59] C.A. Suarez-Quian, S.R. Goldstein, T. Pohida, P.D. Smith, J.I. Peterson, E. Wellner, M. Ghany and R.F. Bonner, Laser capture microdissection of single cells from complex tissues, Biotechniques 26 (1999), 328-335.

[60] F. Sun, N. Arnheim and M.S. Waterman, Whole genome amplification of single cells: Mathematical analysis of PEP and tagged PCR, Nucleic Acids Res. 23 (1995), 3034-3040.

[61] H. Telenius, N.P. Carter, C.E. Bebb, M. Nordenskjold, B.A. Ponder and A. Tunnacliffe, Degenerate oligonucleotideprimed PCR: General amplification of of target DNA by a single degenerate primer, Genomics 13 (1992), 718-725.

[62] K.R. Tindall and T.A. Kunkel, Fidelity of DNA synthesis by the Thermus aquaticus DNA polymerase, Biochemistry 27 (1988), 6008-6013.

[63] I. Tomlinson and W. Bodmer, Selection, the mutation rate and cancer: Ensuring that the tail does not wag the dog, Nat. Med. 5 (1999), 11-12

[64] M. Vockerodt, M. Soares, H. Kanzler, R. Kuppers, D. Kube, M.L. Hansmann, V. Diehl and H. Tesch, Detection of clonal Hodgkin and Reed-Sternberg cells with identical somatically mutated and rearranged $\mathrm{VH}$ genes in different biopsies in relapsed Hodgkin's disease, Blood 92 (1998), 2899-2907.

[65] B. Vogelstein and K.W. Kinzler, The multistep nature of cancer, Trends Genet. 9 (1993), 138-141.

[66] P.S. Walsh, H.A. Erlich and R. Higuchi, Preferential PCR amplification of alleles: Mechanisms and solutions, PCR Methods Appl. 1 (1992), 241-250. 
[67] D. Wells, J.K. Sherlock, A.H. Handyside and J.D.A. Delhanty, Detailed chromosomal and molecular genetic anlysis of singel cells by whole genome amplification and comparative genomic hybridisation, Nucleic Acids Res. 27 (1999), 1214-1218.

[68] P. Wiegand, J. Domhöver and B. Brinkmann, DNA-degradation in formalinfixierten Geweben, Pathologe 17 (1996), 451-454

[69] C. Williams, F. Ponten, C. Moberg, P. Soderkvist, M. Uhlen, J. Ponten, G. Sitbon and J. Lundeberg, A high frequency of sequence alterations is due to formalin fixation of archival specimens. Am. J. Pathol. 155 (1999), 1467-1471.

[70] V.L. Wilson, Q. Wie, K.R. Wade, M. Chisa, D. Bailey, C.M. Canstrup, X. Yin, C.A. Jackson, B. Thompson and W.R. Lee, Needle-in-a-haystack detection and identification of base sub- stitution mutations in human tissues, Mutat. Res. 406 (1999), 79-100.

[71] L. Zhang, X. Cui, K. Schmitt, R. Hubert, W. Navidi and N. Arnheim, Whole genome amplification from a single cell: Implications for genetic analysis, Proc. Natl. Acad. Sci. USA 89 (1992), 5847-5851.

[72] X. Zhong, P.M. Lizardi, X. Huang, P.L. Bray-Ward and D.C. Ward, Visualization of oligonucleotide probes and point mutations in interphase nuclei and DNA fibers using rolling circle DNA amplification, Proc. Natl. Acad. Sci. USA 98 (2001), 3940-3945. 


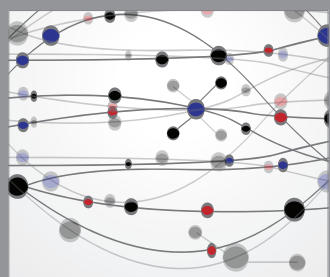

The Scientific World Journal
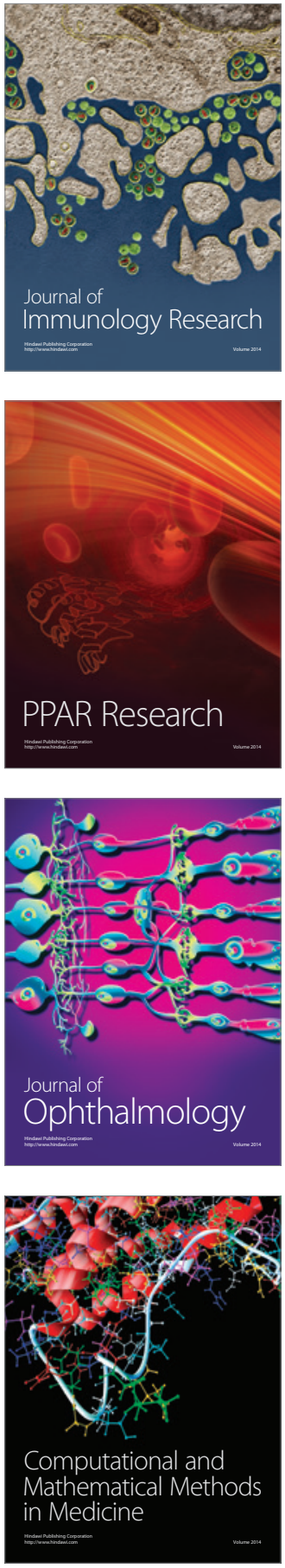

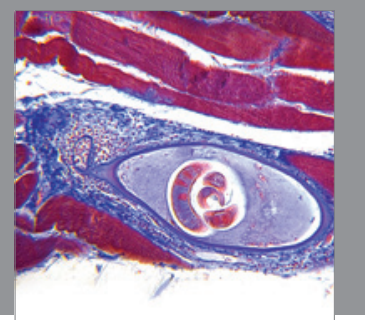

Gastroenterology

Research and Practice
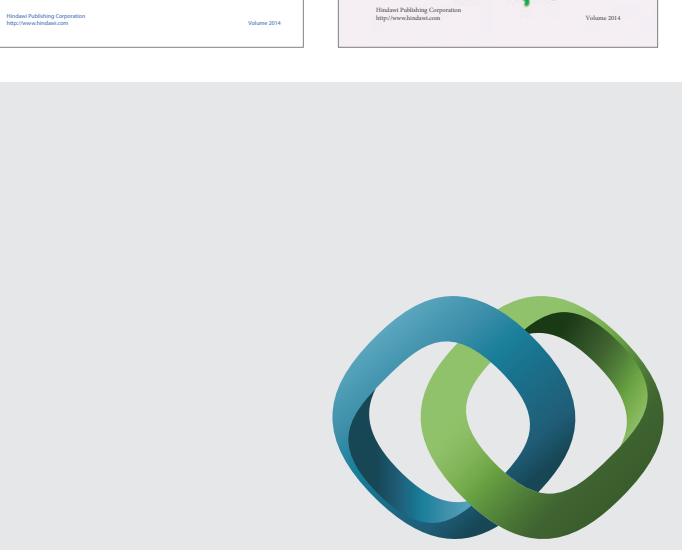

\section{Hindawi}

Submit your manuscripts at

http://www.hindawi.com
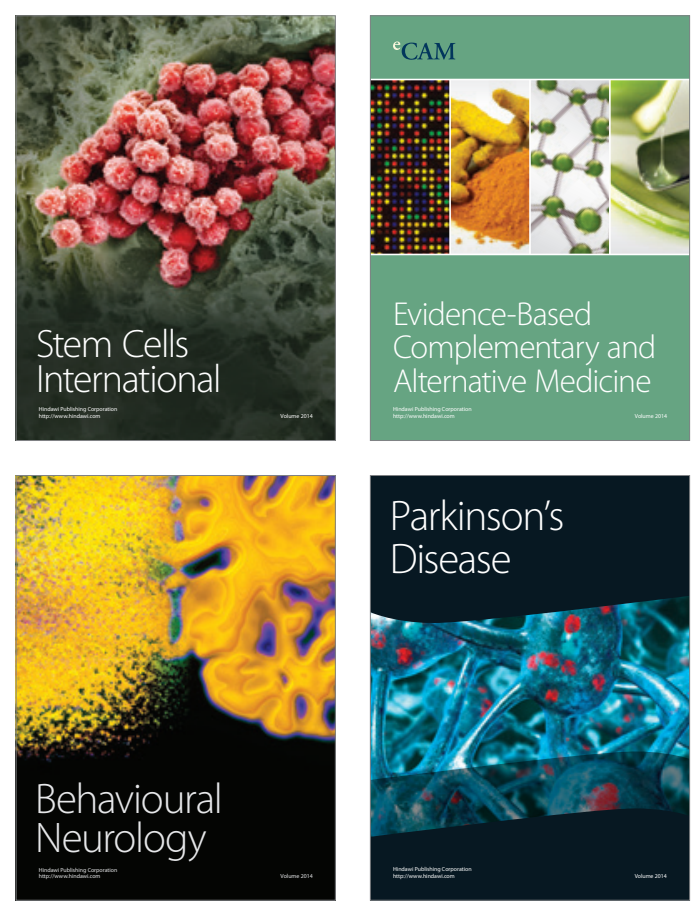

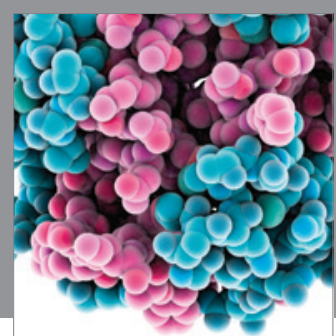

Journal of
Diabetes Research

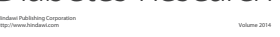

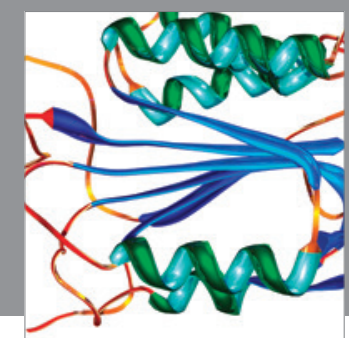

Disease Markers
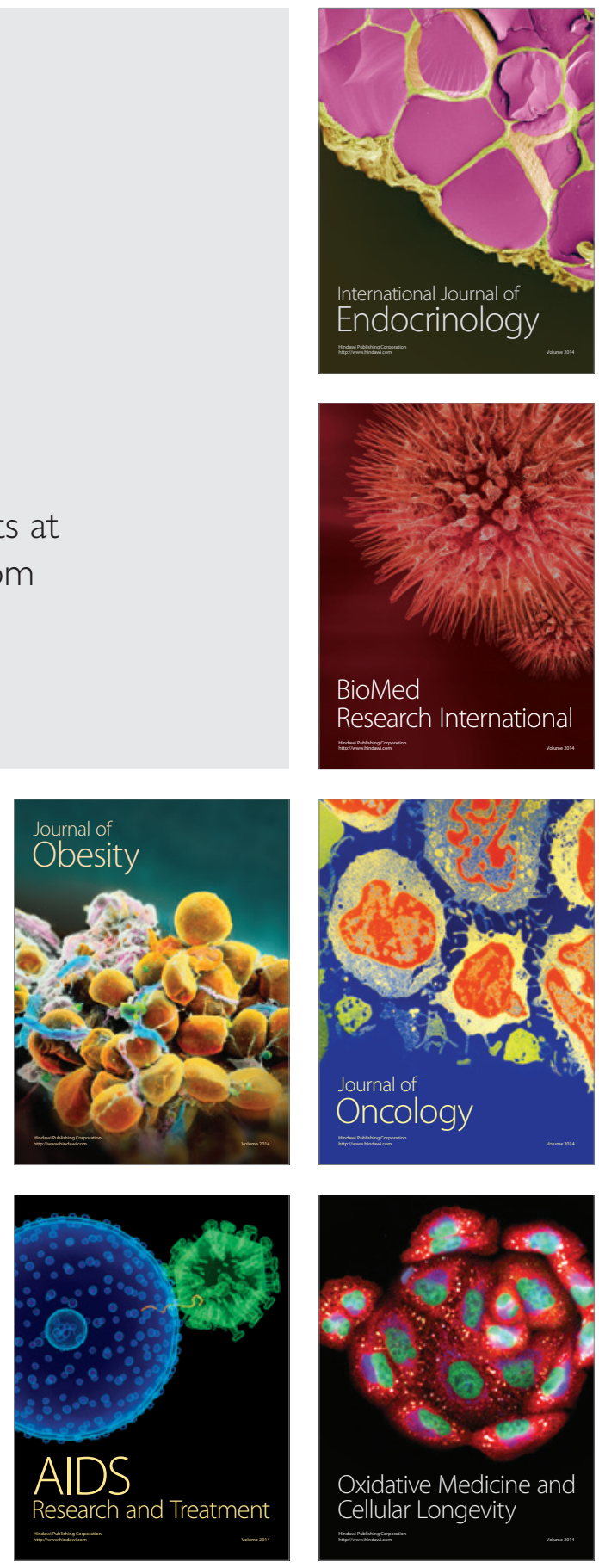